\title{
Ex Vivo Gene Therapy for Skeletal Regeneration in Cranial Defects Compromised by Postoperative Radiotherapy
}

\author{
BRIAN NUSSENBAUM,${ }^{1}$ R. BRUCE RUTHERFORD,${ }^{2}$ THEODOROS N. TEKNOS, ${ }^{3}$ \\ KENNETH J. DORNFELD, ${ }^{4}$ and PAUL H. KREBSBACH ${ }^{5}$
}

\begin{abstract}
Because radiation remains a common postoperative treatment for head and neck cancers, it is critical to determine whether new bone-regenerative approaches are effective for healing craniofacial defects challenged by therapeutic doses of radiation. The objective of this study was to determine whether the deleterious effects of radiotherapy could be overcome by $e x$ vivo gene therapy to heal craniofacial defects. Rat calvarial criticalsized defects were treated with either an inlay calvarial bone graft or syngeneic dermal fibroblasts transduced ex vivo with an adenovirus engineered to express bone morphogenetic protein 7 (BMP-7), a morphogen known to stimulate bone formation. Two weeks postoperatively, either no radiation or a single 12-Gy radiation dose was delivered to the operated area and the tissue was harvested 4 weeks later. None of the inlay bone grafts healed at the wound margins of either the radiated or nonradiated sites. In contrast, bone was successfully regenerated when using an ex vivo gene therapy approach. More bone formed in the nonradiated group as determined by the percentage of defect surface covered $(87 \pm 4.1$ versus $65 \pm 4.7 \% ; p=0.003)$ and percentage of defect area filled by new bone $(60 \pm 5.9$ versus $32 \pm 2.7 \% ; p=0.002)$. Although the effects of radiation on the wound were not completely overcome by the gene therapy approach, bone regeneration was still successful despite the radiation sensitivity of the fibroblasts. These results indicate that BMP-7 ex vivo gene therapy is capable of successfully regenerating bone in rat calvarial defects even after a therapeutic dose of radiation. This approach may represent a new strategy for regenerating skeletal elements lost due to head and neck cancer.
\end{abstract}

\section{OVERVIEW SUMMARY}

Future reconstructive approaches will depend on the development of tissue-regenerativestrategies using protein, cell, or gene therapy. Many advances have been made in tissue engineering, but whether these techniques will be successful in wounds compromised by radiotherapy is still unknown. This issue is particularly important when considering the application for craniofacial or mandibular reconstruction, because these defects most commonly arise from cancer surgery, for which postoperative radiotherapy is often required. Previous studies have shown that protein therapy alone, using bone morphogenetic protein (BMP), does not heal irradiated bone defects. In this study, we determined whether $e x$ vivo adenoviral gene therapy using rat fibroblasts genetically engineered to express BMP-7 could heal critical-size calvarial defects treated with a therapeutically equivalent radiation dose. Our results show that, despite significant radiosensitivity of the transplanted fibroblasts, bone can be successfully regenerated by an ex vivo gene therapy approach. This approach alone does not completely overcome the detrimental effects of radiation, however, as less effective healing was measured at 4 weeks postradiation compared with the well-healed gene therapy-treated nonradiated defects.

\footnotetext{
${ }^{1}$ Department of Otolaryngology, Washington University School of Medicine, St. Louis, MO 63110.

${ }^{2}$ Department of Cariology, University of Michigan School of Dentistry Ann, Arbor, MI 48109.

${ }^{3}$ Department of Otolaryngology, University of Michigan School of Medicine, Ann Arbor, MI 48109.

${ }^{4}$ Department of Radiation Oncology, University of Michigan School of Medicine, Ann Arbor, MI 48109.

${ }^{5}$ Department of Oral Medicine/Pathology/Oncology, University of Michigan School of Dentistry, Ann Arbor, MI 48109.
} 


\section{INTRODUCTION}

A CQUIRED CRANIOFACIAL and mandibular defects are physically, emotionally, and financially devastating to patients. Significant bone defects requiring reconstructive surgery most commonly arise from resection of cancers and bone grafting is usually necessary. As opposed to other skeletal defects that require bone grafts, head and neck cancer defects are unique because these wounds are contaminated with oral bacteria and are likely to be treated with pre- or postoperative radiotherapy. Because of these wound characteristics, nonvascularized, autologous bone grafts have a failure rate that approaches $50 \%$ when placed in the primary setting (Lawson et al., 1982). The success rate is better when the graft is placed months or years later, but subsequent tissue scarring and fibrosis limit the functional and aesthetic outcomes of secondary reconstruction (Adamo and Szal, 1979).

The success of primary reconstruction is improved if microsurgical techniques are used to immediately restore circulation to the bone graft (Urken et al., 1998). These grafts, known as free tissue transfers, can also include soft tissue for reconstruction of accompanying mucosal or cutaneous defects. Free tissue transfer has gained acceptance for reconstructing oromandibular and major craniofacial defects arising from ablative cancer surgery because of the disappointing results of nonvascularized bone grafting for these indications. This approach has some limitations, however, that restrict its universal use. Microvascular reconstruction requires the expert skills of a surgeon specifically trained in this technique and requires several additional hours of operative time. Some patients are not medically capable of tolerating this additional surgery. Despite the surgeon's best efforts, there is a $5-10 \%$ failure rate due to clot formation in the reconnected blood vessels (Urken et al., 1998, 2001). There are multiple defect-and patient-relatedfactors that are important for surgical planning, but the need for bone restricts the flap choices to the scapula, iliac crest, fibula, or radial sites. Finally, harvest of bone from these donor sites can cause significant donor site morbidity such as chronic pain, paresthesias, extremity movement problems, gait disturbances, abdominal wall hernia, and limb ischemia.

On the basis of multicenter randomized clinical trials, human recombinant protein therapy using commercially available bone morphogenetic proteins (BMPs) is now an acceptable alternative to autologous bone grafts for limited orthopedic indications (Friedlaender et al., 2001; Burkus et al., 2002). This treatment is still experimental, however, as a substitute for bone grafting in the craniofacial and mandibular regions. There have been some promising results when used for alveolar ridge (Howell et al., 1997) and sinus floor augmentation (Boyne et al., 1997), but the size of these defects is not comparable to those resulting from ablative cancer surgery or major trauma. Preclinical studies have shown successful healing of criticalsized mandibular (Toriumi et al., 1991) and calvarial defects (Sato and Urist, 1985) in canines, and of mandibular defects in monkeys (Boyne et al., 1999; Marukawa et al., 2002), using BMP delivered on biodegradable carriers. There is also a case report of a patient that had a $6-\mathrm{cm}$ lateral mandibular discontinuity defect from an ameloblastoma resection reconstructed with a BMP bioimplant rather than by vascularized free tissue transfer (Moghadam et al., 2001). Although these findings are promising, the wound environment in these animal models and the case report was optimized to provide an ideal milieu for bone regeneration. This is not customary for patients with ablative head and neck surgical defects. The local vascular and mesenchymal cell environment is likely to be adversely affected by adjuvant radiation therapy, microbiological contamination, and advanced patient age. The defects tend to exceed critical size and also include the overlying periosteum and soft tissues. These patients tend to have a significant tobacco exposure history and comorbidities such as diabetes and peripheral vascular disease, which also adversely affect wound healing.

There is limited information about the ability of osteoinductive protein therapy to successfully heal wounds compromised by pre- or postoperative radiotherapy. There is concern that a single exposure to an exogenous growth factor may not provide an adequate osteoinductive response in the cells within the wound microenvironment to overcome the negative effects of radiotherapy. Animal studies investigating the effects of preoperative radiotherapy validate this concern (Khouri et al., 1996; Wurtzler et al., 1998). These studies model the scenarios of bone reconstruction for osteoradionecrosisand for patients who fail primary treatment with radiotherapy and subsequently require salvage surgery that requires resection of bone. Animal studies investigating the effects of postoperative radiotherapy are lacking but especially important because cancer that is invading bone at the time of presentation is optimally treated by surgical resection and postoperative radiotherapy. This is in accordance with guidelines from the National Comprehensive Cancer Network and consistent with the view of most head and neck oncologists that primary radiotherapy alone cannot provide acceptable local control rates when bone is invaded by tumor.

The use of gene therapy to deliver a gene or gene product is a powerful and potentially effective method to enhance regeneration of skeletal tissues that are compromised by postoperative radiotherapy. In fact, ex vivo (Krebsbach et al., 2000) and in vivo (Alden et al., 2000; Lindsey, 2001) gene therapy approacheshave already been successfully used to heal experimental craniofacial defects in animal models. The ex vivo approach has many advantages including direct delivery of the osteoinductive gene to the desired site, targeting of cells for gene delivery, supplying of cells that directly participate in the osteoinductive process, and, potentially, control of the rate or extent of gene expression by using inducible delivery vectors (Scaduto and Lieberman, 1999). Prior studies performed in our laboratory showed that ex vivo gene therapy using fibroblasts transduced with an adenovirus expressing BMP-7 (AdCMVBMP-7) successfully healed 9-mm rat calvarial critical-sized defects (Krebsbach et al., 2000). We have also shown that a fraction of these genetically modified fibroblasts convert to osteoblasts, and thus directly participate in the bone-regenerative process (Rutherford et al., 2002). The use of an adenovirus vector in ex vivo gene therapy for bone regeneration provides a continuous, yet transient, period of growth factor production, thus enabling a more robust osteoinductive stimulus than protein therapy. Therefore, we hypothesized that an ex vivo gene therapy approach using an adenoviral vector containing the cDNA for BMP-7 would successfully heal craniofacial defects despite their being severely compromised by postoperative radiotherapy. 


\section{MATERIALS AND METHODS}

\section{Generation of recombinant adenovirus}

AdCMVBMP-7 was constructed by Cre-lox recombination as previously described (Franceschi et al., 2000). Briefly, a fulllength mouse BMP-7 cDNA was cloned into pAdlox to produce pAdlox BMP-7 (Hardy et al., 1997). pAdlox and $\psi 5$ virus were cotransfected into CRE8 cells. A plaque assay was used to purify virus from the cell lysate and serial dilutions were used to infect 293 cells. Positive plaques were purified by $\mathrm{CsCl}$ gradient ultracentrifugation. Purified virus was stored in glycerol phosphate-buffered saline and titered by the method described above.

\section{Preparation of rat dermal fibroblasts and adenoviral infection}

Operations were performed under anesthesia with ketamine $(50 \mu \mathrm{g} / \mathrm{g})$ and xylazine $(5 \mu \mathrm{g} / \mathrm{g})$. A paramedian skin incision approximately $2 \mathrm{~cm}$ in length was made on the dorsum and a subcutaneous pocket was bluntly created. Harvested dermis was placed in complete medium (Dulbecco's modified Eagle's medium [DMEM] supplemented with penicillin, streptomycin, and $10 \%$ fetal calf serum) and fibroblast strains were generated from primary explants. The incisions were closed with surgical staples. Cells from passages 4-12 were harvested, counted with a hemocytometer, and frozen for later use or replated, transduced, and seeded directly onto gelatin sponges (Gelfoam; Upjohn, Kalamazoo, MI). The transduction was performed ex vivo for $24 \mathrm{hr}$, using a multiplicity of infection (MOI) of 1000 PFU/cell. Cells were $80-90 \%$ confluent at the time of transduction.

Each gelatin sponge was designed to be a $9 \times 9 \mathrm{~mm}$ disk. The sponges were prewetted in complete medium and air bubbles were removed by applying gentle pressure on the sponge between two pieces of sterile filter paper. Two million transduced cells were collected, suspended in $50 \mu$ l of collagen (2.5 $\mathrm{mg} / \mathrm{ml}$, rat tail collagen, type I; BD Biosciences, Bedford, MA), and loaded onto each sponge by capillary action. All procedures involving animals were performed in accordance with protocols approved by the Unit for Laboratory Animal Medicine (University of Michigan, Ann Arbor, MI).

\section{Repair of craniotomy defects with genetically modified fibroblasts or autologous inlay calvarial bone grafts}

Fischer rats weighing approximately $200 \mathrm{~g}$ were anesthetized with ketamine $(50 \mu \mathrm{g} / \mathrm{g})$ and xylazine $(5 \mu \mathrm{g} / \mathrm{g})$. A linear scalp incision was made from the nasal bone to the occiput and fullthickness flaps were elevated. The periosteum overlying the calvarial bone was completely resected. A trephine was used to produce a 9-mm craniotomy defect centered on the sagittal sinus and the wounds were copiously irrigated with Hanks' balanced salt solution (HBSS) while drilling. The calvarial disk was removed carefully in order to avoid injury to the underlying dura or brain. For rats undergoing bone graft surgery, the calvarial disks were copiously irrigated with HBSS and placed in the proper orientation back into the craniotomy defects. For rats undergoing treatment with ex vivo gene therapy, gelatin sponges previously loaded with transduced syngeneic fibroblasts were placed into the defects. The sponges filled the entire defect and touched the bone edges around the entire periphery. The incisions were closed with 5-0 Vicryl suture (Ethicon/Johnson \& Johnson, Sommerville, NJ) and the rats recovered from anesthesia under a heat lamp.

\section{Animal irradiation}

For rats in the radiation treatment group, a single 12-Gy dose from a cobalt source $\left({ }^{60} \mathrm{Co}\right)$ was delivered to $D_{\max }$ at a sourceto-skin distance of $80 \mathrm{~cm}$ in an 11.47-min exposure. Radiation was delivered exclusively to the surgical site. The pharynx and the rest of the body were shielded by a combination of beam collimation and Cerrobend blocks (Fields et al., 2000). Rats were anesthetized with ketamine $(50 \mu \mathrm{g} / \mathrm{g})$ and xylazine $(5$ $\mu \mathrm{g} / \mathrm{g}$ ) during the radiation treatment. The radiation dose was given 2 weeks after the surgical procedure. Side effects from the radiation were monitored afterward, and included weight loss, wound-healing problems, tissue necrosis, alopecia, ocular problems, and unusual behavior.

\section{Tissue harvest and histology}

Calvaria were harvested 4 weeks after surgery in nonradiated rats and 6 weeks after surgery in radiated animals (4 weeks after radiation). This experimental design maintained a consistent time interval to allow for bone regeneration after the last insult to the defect. The rats were euthanized with $\mathrm{CO}_{2}$ gas. Skin was separated from the underlying skull, and the amount of wound healing was grossly estimated. Calvaria were harvested with a dental drill equipped with a carbide cutting burr, maintaining a minimal 2-mm margin peripheral to the craniotomy site. The harvested bone was irrigated with sterile saline and fixed in buffered zinc formalin (Z-Fix; Anatech, Battle Creek, MI) overnight. Radiographs were taken of each specimen after fixation. The tissue was rinsed in water and then decalcified in $10 \%$ formic acid for 14-17 days. After decalcification, the tissue was divided in the coronal plane immediately in the center of the defect and embedded in paraffin. Five-micron sections were made and placed on 10 slides with 3 sections per slide. The tissue was deparaffinized,hydrated, and the first, fifth, and tenth slides were stained with hematoxylin and eosin.

\section{Histomorphometry and polarized light microscopy}

Computer-assisted bone histomorphometry was performed with a Nikon Eclipse E800 microscope (Nikon, Melville, NY) and Image-Pro Plus 4.1 software (Media Cybernetics, Silver Spring, MD). The third section on the fifth slide, which approximated the midline cut, was used for each rat. Wound healing was quantified by measuring the percentage of defect surface covered by bone (length of bone regenerated across the defect divided by total length of defect) and the percentage of defect area filled by new bone (area of bone regenerated in the defect divided by total area of the defect). The amount of osteosynthesis at the wound margins was also qualitatively assessed. The data for the percentage of defect surface covered by bone were analyzed by an unpaired $t$ test, and the percentage of defect area filled by new bone was analyzed by an un- 
A

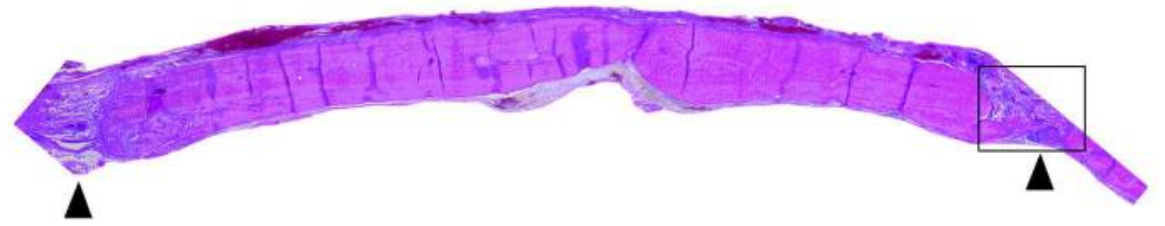

FIG. 1. Inlay calvarial bone grafts fail to heal critical-size calvarial defects independent of radiation treatment. (A) Nonirradiated cranial defect treated with an autologous inlay calvarial bone graft. Solid arrowheads designate the surgical margins. Original magnification, $\times 4$. (B) Right wound margin corresponding to the boxed area in (A), revealing fibrous union. Original magnification, $\times 40$.
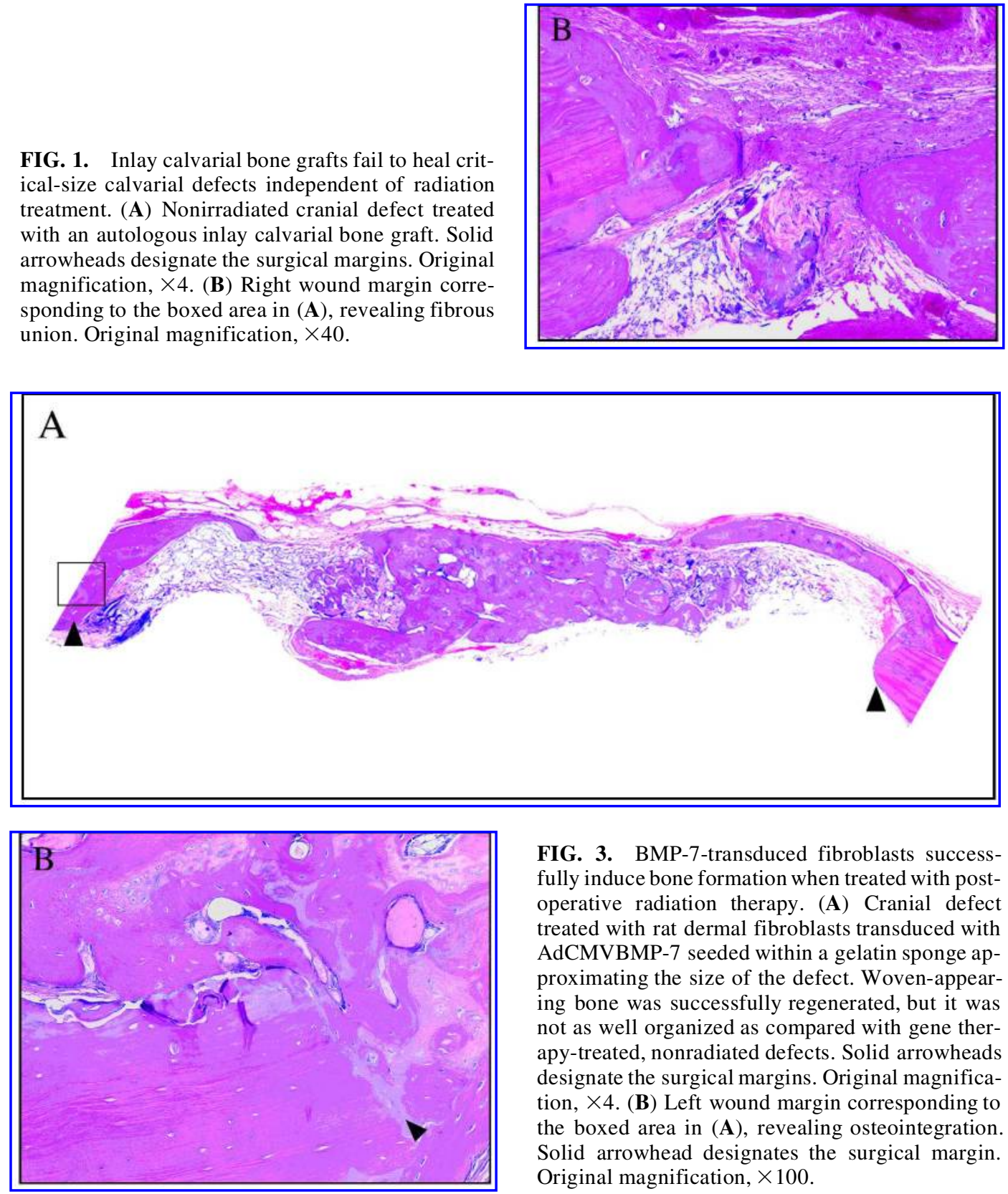

FIG. 3. BMP-7-transduced fibroblasts successfully induce bone formation when treated with postoperative radiation therapy. (A) Cranial defect treated with rat dermal fibroblasts transduced with AdCMVBMP-7 seeded within a gelatin sponge approximating the size of the defect. Woven-appearing bone was successfully regenerated, but it was not as well organized as compared with gene therapy-treated, nonradiated defects. Solid arrowheads designate the surgical margins. Original magnification, $\times 4$. (B) Left wound margin corresponding to the boxed area in (A), revealing osteointegration. Solid arrowhead designates the surgical margin. Original magnification, $\times 100$. 


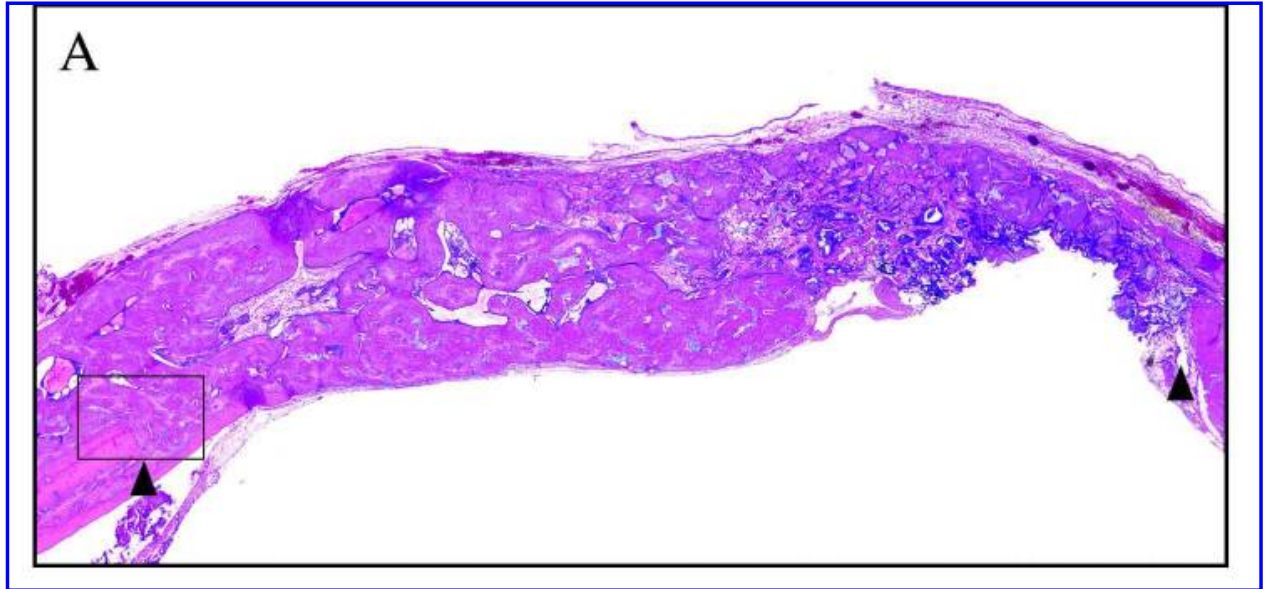

FIG. 2. BMP-7-transduced fibroblasts heal calvarial critical-size defects not treated with radiation therapy. (A) Cranial defect repair with rat dermal fibroblasts transduced with AdCMVBMP-7 seeded within a gelatin sponge approximating the size of the defect. Confluent bone nearly crosses the entire defect. The solid arrowheads designate the surgical margins. Original magnification, $\times 4$. (B) Left wound margin corresponding to the boxed area in (A), revealing osteointegration.Solid arrowhead designates the surgical margin. Original magnification, $\times 100$. (C) Central portion of the regenerated bone at 1 month, with marrow-appearing spaces admixed with the new bone. Original magnification, $\times 100$. (D) Polarized light microscopy through the central portion of regenerated bone at 1 month. Collagen fibers are organized in a pattern consistent with woven bone. Original magnification, $\times 100$. (E) Central portion of the regenerated bone at 6 months, with remodeling of bone to a lamellar appearance and Haversian canal formation. Original magnification, $\times 63$. (F) Polarized light microscopy through the central portion of regenerated bone at 6 months. Collagen fibers are organized in a pattern consistent with lamellar bone. Original mag-

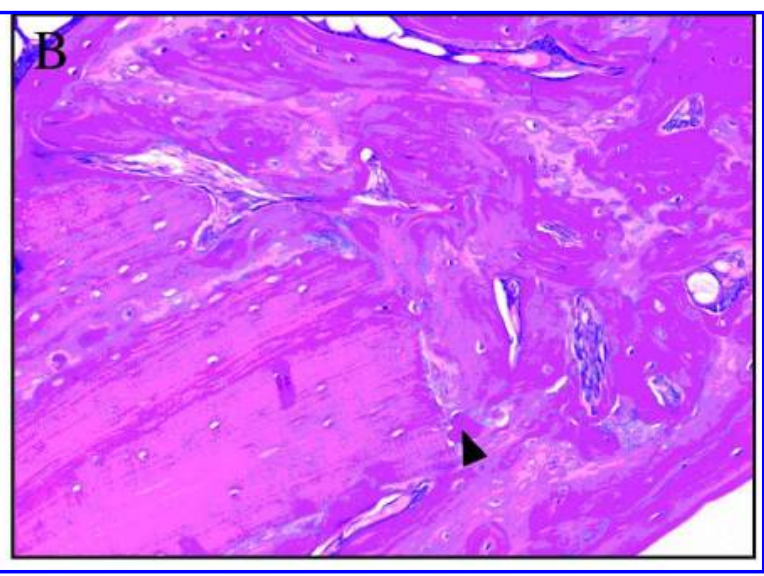
nification, $\times 63$.
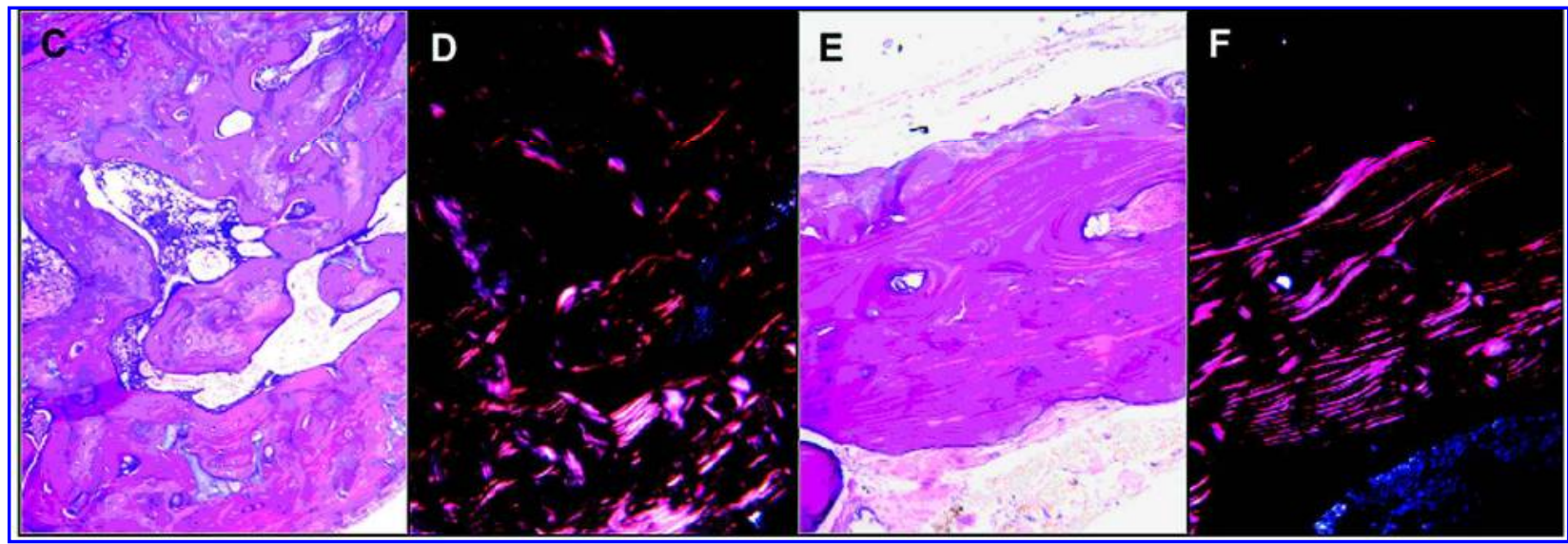
paired $t$ test with Welch correction (GraphPad InStat version 3.0a for the Macintosh; GraphPad Software, San Diego, CA). Data are presented as means \pm SEM.

Polarized light microscopy was performed on tissue specimens from rat calvarial critical-sized defects treated with BMP7-transduced fibroblasts harvested at 1 month $(n=1)$ and at 6 months $(n=1)$ postoperatively. A Leitz Aristoplan optical microscope (Leica Microsystems, Wetzlar, Germany) was used and electronic image capture was performed with a SPOT-RT digital camera (Diagnostic Instruments, Sterling Heights, MI).

\section{Radiation sensitivity}

A limiting dilution assay was performed to determine the radiation sensitivity of rat dermal fibroblasts (Grenman et al., 1989). This technique was used because rat dermal fibroblasts do not tend to form colonies in vitro. Briefly, single-cell suspensions of fibroblasts (passage 11) were radiated in complete medium. Radiation doses of 0,6 , and 12 Gy were used. For each radiation dose, cells were then plated into 96-well plates at concentrations of $6,12,18$, and 24 cells/well in $200 \mu$ l of complete medium. For each cell concentration, the central 60 wells were plated with cells and the peripheral 36 wells received $200 \mu \mathrm{l}$ of distilled deionized $\mathrm{H}_{2} \mathrm{O}$. The plates were kept in an incubator at $37^{\circ} \mathrm{C}$ in a water vapor-saturated room air atmosphere containing $5 \% \mathrm{CO}_{2}$. The plates were examined with an inverted phase-contrast microscope at 17 days. A well was considered positive if a colony in it reached a size of 32 cells or more. The plating efficiency was calculated according to the formula $\mathrm{PE}=-\ln$ (negative wells/total wells)/number of cells plated per well (Thilly et al., 1980). The fraction survival was determined by dividing the plating efficiency at each radiation dose by the plating efficiency for $0 \mathrm{~Gy}$. The experiment was repeated twice.

\section{RESULTS}

\section{Tolerance of rats to radiotherapy}

All rats that received radiation experienced a weight loss of 10-15 g during the first week after treatment, but then gained weight appropriately during the subsequent weeks before tissue harvest. The radiation caused mild alopecia of the scalp but no skin-healing problems or infections occurred. No rats experienced overt signs of pharynx or ocular toxicity from the radiation.

\section{Autologous bone grafts fail to heal craniotomy defects independent of radiation treatment}

At the time of tissue harvest, none of the inlay calvarial bone grafts in nonradiated $(n=5)$ or radiated $(n=5)$ craniotomy defects presented gross evidence of healing at the wound margins. The surfaces of these grafts were flush with the surrounding bone, but were mobile. Histology revealed intact bone grafts with viable osteocytes, but fibrous union with minimal osteogenesis at the wound margins (Fig. 1).

\section{BMP-7-transduced fibroblasts heal calvarial defects not treated with radiation therapy}

At the time of tissue harvest, bone healing was estimated as nearly $100 \%$ by gross inspection $(n=8)$ for the craniotomy de- fects treated with fibroblasts genetically modified to express BMP-7. Confluent bone spanned across the entire defect and, in many cases, the exact wound margins were difficult to identify because of excellent healing at the edges. This new bone was not mobile. Histology revealed confluent bone spanning the defect, with excellent osteointegrationat many of the wound margins (Fig. 2A and B). The regenerated bone appeared woven when harvested 1 month after surgery (Fig. 2C and D), but this bone remodeled to form lamellar bone when harvested 6 months later (Fig. 2E and F). No overt immune or inflammatory response was seen histologically in the ex vivo gene therapy-treated animals. Histomorphometric analysis revealed that the mean defect surface covered by bone was $87 \pm 4.1 \%$ and the mean defect area filled by new bone was $60 \pm 5.9 \%$.

\section{BMP-7-transduced fibroblasts successfully induce bone formation when treated with radiation therapy after transplantation}

Fibroblasts genetically modified to express BMP-7 successfully induced new bone formation in craniotomy defects subsequently treated with a therapeutically equivalent dose of radiation $(n=10)$. This ex vivo gene therapy approach, however, was less effective compared with the results for nonradiated animals. At the time of tissue harvest, bone healing was estimated as $50-100 \%$ and islands of new bone were more common than confluent areas spanning the entire defect. Histology revealed woven-appearingbone formation that was not as well organized or healed at the wound edges as compared with nonradiated $e x$ vivo gene therapy-treated defects (Fig. 3). Histomorphometric analysis revealed that the mean defect surface covered by bone was $65 \pm 4.7 \%$ and the mean defect area filled by new bone was $32 \pm 2.7 \%$. Statistical analysis confirmed that this group experienced significantly less bone regeneration when compared with defects not treated with radiation (Fig. 4).

\section{In vitro radiation sensitivity of rat dermal fibroblasts}

A limiting dilution assay was performed in order to determine the radiation sensitivity of rat dermal fibroblasts. The fraction survival for a single 12-Gy radiation dose was a 2-log kill ratio (Fig. 5). Despite this finding, ex vivo gene therapy using fibroblasts still provided a robust osteoinductive signal that stimulated good bone regeneration in these radiated defects.

\section{DISCUSSION}

This animal model was used to investigate whether an ex vivo gene therapy approach to regenerate bone in critical-size defects would be successful if a therapeutic dose of postoperative radiation was given. A single dose of 12 Gy was used because of logistic problems in delivering fractionated radiation to rats, an estimation that this single dose for a rat was equivalent to a fractionated 60-Gy dose for a human, and prior studies that have shown that this is a safe dose for cranial irradiation in rats (Remsen et al., 1995). No rats experienced cutaneous wound dehiscence or ocular toxicity, and effective shielding of the snout prevented mucosal toxicity.

Despite receiving a therapeutic dose of postoperative radiation, BMP-7 ex vivo gene therapy successfully regenerated bone in rat calvarial critical-size defects. Although the detrimental 


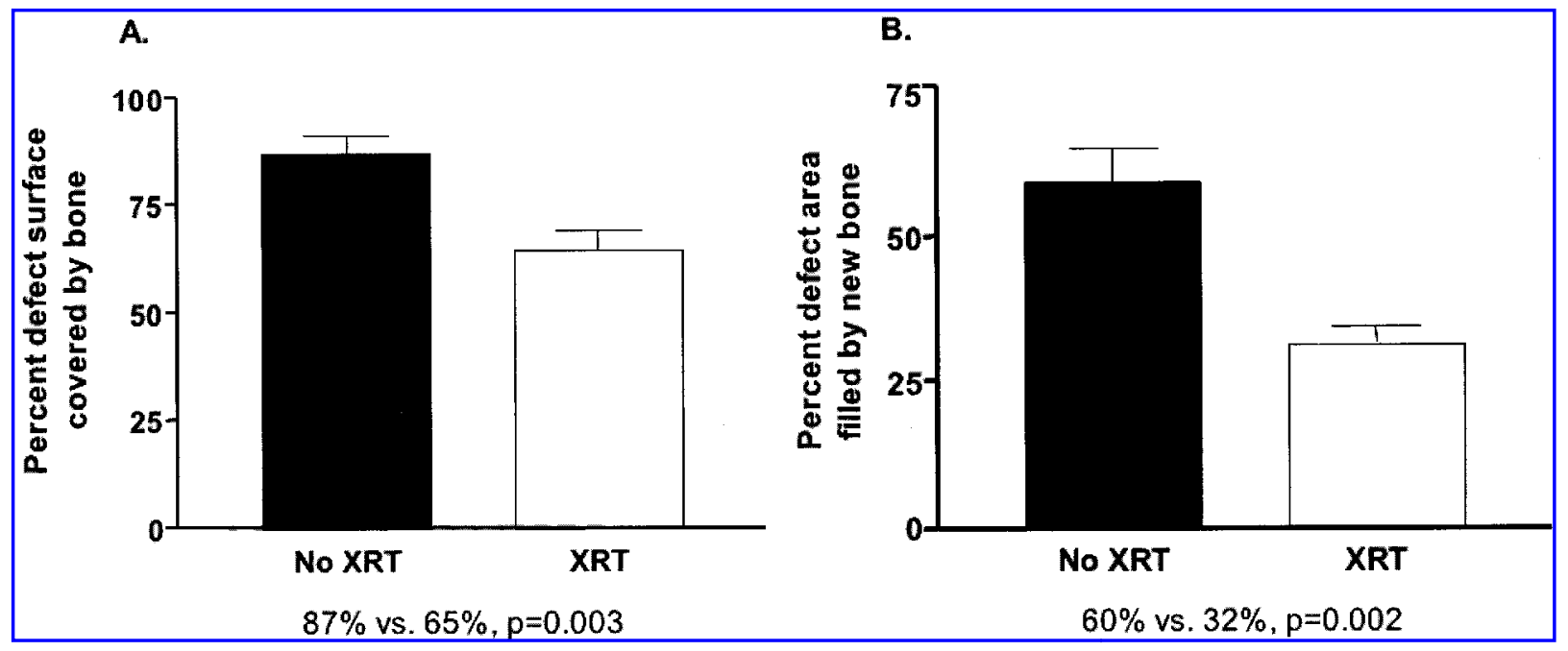

FIG. 4. Histomorphometric analysis of new bone formation in calvarial defects. The bar graphs compare ex vivo gene therapytreated defects that did not receive radiation with ex vivo gene therapy-treated defects that received postoperative radiation. Quantification was performed by computer-assisted bone histomorphometry. (A) Percentage of defect surface covered by bone. (B) Percentage of defect area healed. XRT, radiation therapy.

effects of radiation were not completely overcome by the gene therapy approach, this regeneration was remarkable given the significant radiation sensitivity of the transplanted fibroblasts used to deliver the gene into the wound. The control group received an inlay bone graft because this is an accepted treatment option in patients and prior studies have shown that fibroblasts genetically modified to express lac $Z$ did not show any evidence of bone regeneration when placed in critical-size rat calvarial defects (Krebsbach et al., 2000). The inlay autologous bone grafts did not heal in this defect model independent of radiation exposure. This may be related to not providing rigid fixation for these grafts (Abbott et al., 1994; DeLuca et al., 1997) or may be due to removal of the periosteum (Hopper et al., 2001). Excellent healing in the gene therapy-treated defects still occurred despite nonrigid scaffold fixation and periosteum resection.
Patients with large craniofacial or mandibular defects resulting from ablative surgery will benefit greatly if regenerative medicine can successfully be applied for bone regeneration. Potential advantages over current treatments involving vascularized or nonvascularizedautologous bone grafting include avoidance of donor site morbidity, decreased operative time, decreased surgical complications, and custom fabrication of the reconstructed segment to recapitulate the three-dimensional shape of the resected bone. The surgeon would also be able to choose from a greater variety of flaps for soft tissue reconstruction, rather than being limited to the fibula, iliac crest, scapula, or radial donor sites.

Radiation therapy, administered either pre- or postoperatively, is an integral part of comprehensive treatment for advanced-stage head and neck malignancies, and thus the nega-

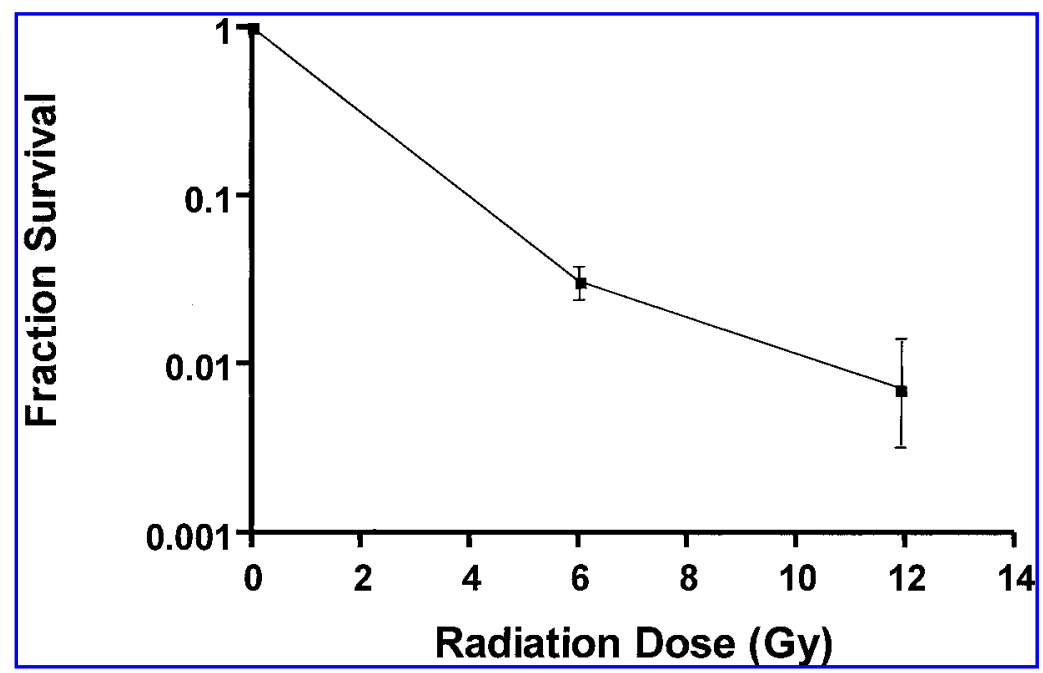

FIG. 5. Radiation survival curve of rat dermal fibroblasts measured by limiting dilution assay. There is an approximately 2$\log$ kill ratio at a dose of $12 \mathrm{~Gy}$. 
tive effects of radiotherapy on the wound will need to be accounted for when devising strategies for regenerating skeletal elements lost because of head and neck cancer (Denham and Hauer-Jensen, 2002). To date, studies have been limited and have investigated only the use of osteoinductive protein therapy with BMP in previously radiated tissues. Irradiation in vitro up to 8 Gy did not affect BMP-2-induced osteoblast differentiation of $\mathrm{C} 2 \mathrm{C} 12$ cells (Ikeda et al., 2000), and bone growth still occurred on a BMP-2-treated hydroxyapatite disk implanted into a rabbit snout subperiosteal pocket radiated preoperatively with a fractionated dose of $20 \mathrm{~Gy}$ (Howard et al., 1998). Unfortunately, results with orthotopic defects are not as encouraging. Using the rat calvarium, 3-mm defects treated with a preoperative 12-Gy radiation dose and subsequently with BMP-2 had successful bone regeneration but incomplete healing of the defects (Wurzler et al., 1998). In a 4-mm rat mandible defect treated with a fractionated 45-Gy radiation dose and 2 weeks later with demineralized bone powder, only $39 \%$ of defects had more than $50 \%$ bone fill (Lorente et al., 1992). Using a 7-mm rat calvarial defect, Khouri et al. showed that microvascular transfer of a muscle flap in addition to treatment with BMP-3 allowed for complete healing of the defect despite receiving a single preoperative $15-$ Gy radiation dose (Khouri et al., 1996). Treatment with no implant, a microvascular muscle flap alone, or BMP-3 alone did not heal the defect. Collectively, these findings suggest that a well-vascularized environment with a population of responsive cells needs to be restored in addition to delivering BMP for complete wound healing to occur using osteoinductive protein therapy.

Ex vivo gene therapy is an alternative tissue-regenerativeapproach that may be advantageous for healing compromised wounds. Ex vivo gene therapy can provide a period of sustained BMP production, thus enabling the host's wound to respond to the osteoinductive stimulus in a more robust fashion compared with when a single dose is delivered by protein therapy (Scaduto and Lieberman, 1999). Although there are craniofacial defect models showing success with in vivo approaches (Alden et al., 2000; Lindsey, 2001), an ex vivo gene therapy approach has several advantages including direct delivery of the osteoinductive gene to the desired site, targeting of cells for gene delivery, supplying of cells that directly participate in the reparative process, and the potential to control the rate or extent of gene expression by using inducible delivery vectors (Scaduto and Lieberman, 1999). Because of these advantages, our laboratory has used the ex vivo approach for delivering genes to modulate bone regeneration. Although different types of cells can be genetically modified to express BMP (Musgrave et al., 2000), fibroblasts were chosen because of the ease of harvest, isolation, and cell culture. Although fibroblasts lack intrinsic responsiveness to BMP-2 (Musgrave et al., 2000), these cells are capable of converting into other tissue lineages, such as osteoblasts, when genetically modified (Rutherford et al., 2002). Thus, in addition to providing the osteoinductivesignal, these cells may also directly participate in the reparative process. Our study did not delineate the extent to which donor or recipient cells were involved in the bone-regenerative process.

The ex vivo gene therapy approach led to significant bone regeneration in this severely compromised, clinically relevant setting. Despite our findings that transduced fibroblasts were extremely radiosensitive at the radiation dose studied, ex vivo gene therapy provided a potent osteoinductive stimulus when examined 6 weeks after surgery. This ex vivo approach, however, was less effective in irradiated animals compared with those not radiated. Future studies will investigate whether bone regeneration in radiated defects eventually becomes equivalent to that in nonradiated defects at later time points. Strategies for enhancing bone regeneration initiated by ex vivo gene therapy in radiationcompromised wounds also need to be investigated. Some promising approaches include increasing the number of genetically modified cells loaded onto the scaffold, using an osteoconductive scaffold, or a scaffold that also allows growth factors to be released in a controlled manner (Oldham et al., 2000; Richardson et al., 2001; Sakiyama-Elbert et al., 2001), delivery of multiple genes (Peng et al., 2002), improving wound vascularity, or the use of radioprotective medications (Forrest et al., 2002), and anabolic hormonal therapy (Schneider et al., 2003).

\section{ACKNOWLEDGMENTS}

We thank Mary Davis, Ph.D., and Susan Rynk for assistance with animal radiation, Chris Strayhorn for assistance with histologic preparation, Ajita Narayan, Ph.D., for assistance with the limiting dilution assay, Abraham Schneider for assistance with histomorphometry, and Colleen Flannagan for assistance with polarized light microscopy. This work was supported by grants DE 13835 (P.H.K.) and DE 12644 (R.B.R.) from the National Institute of Dental and Craniofacial Research. P.H.K. is a recipient of National Institutes of Health Independent Scientist Award DE 00426 sponsored by the National Institute of Dental and Craniofacial Research.

\section{REFERENCES}

ABBOTT, R., LAURENT, J.P., JUDGE, D., and CHEEK, W.R. (1994). Survival of split calvarial bone grafts in a dog model. Childs Nerv. Syst. 10, 249-251.

ADAMO, A.K., and SZAL, R.L. (1979). Timing, results, and complications of mandibular constructive surgery: Report of 32 cases. J. Oral Surg. 37, 755-763.

ALDEN, T.D., BERES, E.J., LAURENT, J.S., ENGH, J.A., DAS, S., LONDON, S.D., JANE, J.A., HUDSON, S.B., and HELM, G.A. (2000). The use of bone morphogenetic protein gene therapy in craniofacial bone repair. J. Craniofac. Surg. 11, 24-30.

BOYNE, P.J., MARX, R.E., NEVINS, M., TRIPLETT, G., LAZARO, E. LILLY, L.C., ADLER, M., and NUMMIKOSKI, P. (1997). A feasibility study evaluating rhBMP-2/absorbable collagen sponge device for maxillary sinus floor augmentation. Int. J. Periodontics Restor. Dent. 17, 11-25.

BOYNE, P.J., NAKAMURA, A., and SHABAHANG, S. (1999). Evaluation of the long-term effect of function on rhBMP-2 regenerated hemimandibulectomy defects. Br. J. Oral Maxillofac. Surg. 37, 344-352.

BURKUS, J.K., TRANSFELDT, E.E., KITCHEL, S.H., WATKINS, R.G., and BALDERSTON, R.A. (2002). Clinical and radiographic outcomes of anterior lumbar interbody fusion using recombinant human bone morphogenetic protein-2. Spine 21, 2396-2408.

DE LUCA, L., RASZEWSKI, R., TRESSER, N., and GUYURON, B. (1997). The fate of preserved autogenous bone graft. Plast. Reconstr. Surg. 99, 1324-1328.

DENHAM, J.W., and HAUER-JENSEN, M. (2002). The radiotherapeutic injury: A complex "wound." Radiother. Oncol. 63, 129-145. FIELDS, M.T., EISBRUCH, A., NORMOLLE, D., ORFALI, A., DAVIS, M.A., PU, A.T., and LAWRENCE, T.S. (2000). Radiosen- 
sitization produced in vivo by once- vs. twice-weekly $2^{\prime} 2^{\prime}$-difluoro2 '-deoxycytidine (gemcitabine). Int. J. Radiat. Oncol. Biol. Phys. 47, 785-791.

FORREST, C.R., O’DONOVAN, D.A., YEUNG, I., ZEMAN, V., LA SCALA, G., NELIGAN, P.C., and PANG, C.Y. (2002). Efficacy of radioprotection in the prevention of radiation-induced craniofacial bone growth inhibition. Plast. Reconstr. Surg. 109, 1311-1323.

FRANCESCHI, R.T., WANG, D., KREBSBACH, P.H., and RUTHERFORD, R.B. (2000). Gene therapy for bone formation: In vitro and in vivo osteogenic activity of an adenovirus expressing BMP7. J. Cell. Biochem. 78, 476-486.

FRIEDLAENDER, G.E., PERRY, C.R., COLE, J.D., COOK, S.D., CIERNY, G., MUSCHLER, G.F., ZYCH, G.A., CALHOUN, J.H., LAFORTE, A.J., and YIN, S. (2001). Osteogenic protein-1 (bone morphogenetic protein-7) in the treatment of tibial nonunions. J. Bone Joint Surg. 83A(Suppl. 1), 151-158.

GRENMAN, R., BURK, D., VIROLAINEN, E., BUICK, R.N., CHURCH, J., SCHWARTZ, D.R., and CAREY, T.E. (1989). Clonogenic cell assay for anchorage-dependent squamous carcinoma cell lines using limiting dilution. Int. J. Cancer 44, 131-136.

HARDY, S., KITAMURA, M., HARRIS-STANSIL, T., DAI, Y., and PHIPPS, M.L. (1997). Construction of adenovirus vectors through Cre-lox recombination. J. Virol. 71, 1842-1849.

HOPPER, R.A., ZHANG, J.R., FOURNASIER, V.L., MOROVAPROTZNER, I., PROTZNER, K.F., PANG, C.Y., and FORREST, C.R. (2001). Effect of isolation of periosteum and dura on the healing of rabbit calvarial inlay bone grafts. Plast. Reconstr. Surg. 107, 454-462.

HOWARD, B.K., BROWN, K.R., LEACH, J.L., CHANG, C., and ROSENTHAL, D.I. (1998). Osteoinduction using bone morphogenetic protein in irradiated tissue. Arch. Otolaryngol. Head Neck Surg. 124, 985-988.

HOWELL, T.H., FIORELLINI, J., JONES, A., ADLER, M., NUMMIKOSKI, P., LAZARO, M., LILLY, L., and COCHRAN, D. (1997). A feasibility study evaluating rhBMP-2/absorbable collagen sponge device for local alveolar ridge preservation or augmentation. Int. J. Periodontics Restor. Dent. 17, 124-139.

IKEDA, S., HACHISU, R., YAMAGUCHI, A., GAO, Y.H., and OKANO, T. (2000). Radiation retards muscle differentiation but does not affect osteoblastic differentiation induced by bone morphogenetic protein-2 in C2C12 myoblasts. Int. J. Radiat. Biol. 76, 403-411.

KHOURI, R.K., BROWN, D.M., KOUDSI, B., DEUNE, E.G., GILULA, L.A., COOLEY, B.C., and REDDI, A.H. (1996). Repair of calvarial defects with flap tissue: Role of bone morphogenetic proteins and competent responding tissues. Plast. Reconstr. Surg. 98, 103-109.

KREBSBACH, P.H., GU, K., FRANCESCHI, R.T., and RUTHERFORD, R.B. (2000). Gene therapy-directed osteogenesis: BMP-7 transduced human fibroblasts form bone in vivo. Hum. Gene Ther. 11, 1201-1210.

LAWSON, W., and BILLER, H.F. (1982). Mandibular reconstruction: Bone graft techniques. Otolaryngol. Head Neck Surg. 90, 589-594.

LINDSEY, W.H. (2001). Osseous tissue engineering with gene therapy for facial bone reconstruction. Laryngoscope 111, 1128-1136.

LORENTE, C.A., SONG, B.Z., and DONOFF, R.B. (1992). Healing of bony defects in the irradiated and unirradiated rat mandible. J. Oral Maxillofac. Surg. 50, 1305-1309.

MARUKAWA, E., ASAHINA, L., ODA, M., SETO, L., ALAM, M., and ENOMOTO, S. (2002). Functional reconstruction of the nonhuman primate mandible using recombinant human bone morphogenetic protein-2. Int. J. Oral Maxillofac. Surg. 31, 287-295.

MOGHADAM, H.G., URIST, M.R., SANDOR, G.K.B., and CLOKIE, C.M.L. (2001). Successful mandibular reconstruction using a BMP bioimplant. J. Craniofac. Surg. 12, 119-127.

MUSGRAVE, D.S., BOSCH, P., LEE, J.Y., PELINKOVIC, D., GHIVIZZANI, S.C., WHALEN, J., NIYIBIZI, C., and HUARD, J. (2000). Ex vivo gene therapy to produce bone using different cell types. Clin. Orthop. Relat. Res. 378, 290-305.
OLDHAM, J.B., LU, L., ZHU, X., PORTER, B.D., HEFFERAN, T.E., LARSON, D.R., CURRIER, B.L., MIKOS, A.G., and YASZEMSKI, M.J. (2000). Biological activity of rhBMP-2 released from PLGA microspheres. J. Biomech. Eng. 122, 289-292.

PENG, H., WRIGHT, V., USAS, A., GEARHART, B., SHEN, H., CUMMINS, J., and HUARD, J. (2002). Synergistic enhancement of bone formation and healing by stem cell-expressed VEGF and bone morphogenetic protein-4. J. Clin. Invest. 110, 751-759.

REMSEN, L.G., MCCORMICK, C.I., SEXTON, G., PEARSE H.D., GARCIA, R., and NEUWELT, E.A. (1995). Decreased delivery and acute toxicity of cranial irradiation and chemotherapy given with osmotic blood-brain barrier disruption in a rodent model: The issue of sequence. Clin. Cancer Res. 1, 731-739.

RICHARDSON, T.P., PETERS, M.C., ENNETT, A.B., and MOONEY, D.J. (2001). Polymeric system for dual growth factor delivery. Nat. Biotechnol. 19, 1029-1034.

RUTHERFORD, R.B., MOALLI, M., FRANCESCHI, R.T., WANG, D., GU, K., and KREBSBACH, P.H. (2002). Bone morphogenetic protein-transduced human fibroblasts convert to osteoblasts and form bone in vivo. Tissue Eng. 8, 441-452.

SAKIYAMA-ELBERT, S.E., PANITCH, A., and HUBBELL, J.A. (2001). Development of growth factor fusion proteins for cell-triggered drug delivery. FASEB J. 15, 1300-1302.

SATO, K., and URIST, M.R. (1985). Induced regeneration of calvaria by bone morphogenetic protein (BMP) in dogs. Clin. Orthop. Relat. Res. 197, 301-311.

SCADUTO, A.A., and LIEBERMAN, J.R. (1999) Gene therapy for osteoinduction. Orthop. Clin. North Am. 30, 625-633.

SCHNEIDER, A., TABOAS, J.M., MCCAULEY, L.K., and KREBSBACH, P.H. (2003). Skeletal homeostasis in tissue-engineered bone. J. Orthop. Res. (in press).

THILLY, W.G., DELUCA, J.G., FURTH, E.E., HOPPE, H., KADEN, D.A., KROLEWSKI, J.J., LIBER, H.L., SKOPEK, T.R., SLAPNIKOFF, S.A., TIZARD, R.J., and PENMAN, B.W. (1980). Genelocus mutation assays in diploid human lymphoblast lines. In Chemical Mutagens, Vol. 6. F.J. de Serres and A. Hollaender, eds. (Plenum, New York) pp. 331-334.

TORIUMI, D.M., KOTLER, H.S., LUXEMBERG, D.P., HOLTROP, M.E., and WANG, E.A. (1991). Mandibular reconstruction with a recombinant bone-inducing factor. Arch. Otolaryngol. Head Neck Surg. 117, 1101-1112.

URKEN, M.L., BUCHBINDER, D., COSTANTINO, P.D., SINHA, U., OKAY, D., LAWSON, W., and BILLER, H.F. (1998). Oromandibular reconstruction using microvascular composite flaps. Arch. Otolaryngol. Head Neck Surg. 124, 46-55.

URKEN, M.L., BRIDGER, A.G., ZUR, K.B., and GENDEN, E.M. (2001). The scapular osteofasciocutaneous flap: A 12-year experience. Arch. Otolaryngol. Head Neck Surg. 127, 862-869.

WURZLER, K.K., DEWEESE, T.L., SEBALD, W., and REDDI, A.H. (1998). Radiation-induced impairment of bone healing can be overcome by recombinant human bone morphogenetic protein-2. J. Craniofac. Surg. 9, 131-137.

Address reprint requests to: Dr. Paul H. Krebsbach Department of Oral Medicine/Pathology/Oncology University of Michigan School of Dentistry 1011 North University Avenue Ann Arbor, MI 48109-1078

E-mail:paulk@umich.edu

Received for publication February 4, 2003; accepted after revision May 13, 2003.

Published online: June 10, 2003. 


\section{This article has been cited by:}

1. Rongying Wang, Yanqiong Zou, Zhen Yuan, Ying Wang, Yuying Chen, Yuanqing Mao, Zhen-An Zhu, Hui Li, Xueming Tang, Jian Lu, Jing Yi. 2009. Autografts and Xenografts of Skin Fibroblasts Delivering BMP-2 Effectively Promote Orthotopic and Ectopic Osteogenesis. The Anatomical Record: Advances in Integrative Anatomy and Evolutionary Biology 292:6, 777-786. [CrossRef]

2. Esther H. Teo, Kevin J. Cross, Elan D. Bomsztyk, David C. Lyden, Jason A. Spector. 2009. Gene Therapy in Skin. Annals of Plastic Surgery 62:5, 576-580. [CrossRef]

3. Ann Leu, Susanne M. Stieger, Paul Dayton, Katherine W. Ferrara , J. Kent Leach . 2009. Angiogenic Response to Bioactive Glass Promotes Bone Healing in an Irradiated Calvarial DefectAngiogenic Response to Bioactive Glass Promotes Bone Healing in an Irradiated Calvarial Defect. Tissue Engineering Part A 15:4, 877-885. [Abstract] [PDF] [PDF Plus]

4. W Lattanzi, C Parrilla, A Fetoni, G Logroscino, G Straface, G Pecorini, E Stigliano, A Tampieri, R Bedini, R Pecci, F Michetti, A Gambotto, P D Robbins, E Pola. 2008. Ex vivo-transduced autologous skin fibroblasts expressing human Lim mineralization protein-3 efficiently form new bone in animal models. Gene Therapy 15:19, 1330-1343. [CrossRef]

5. Mohammed E. Elsalanty, Taher N. Taher, Ibrahim E. Zakhary, Osama A. Al-Shahaat, Mohammed Refai, Hatem A. El-Mekkawi. 2007. Reconstruction of Large Mandibular Bone and Soft-Tissue Defect Using Bone Transport Distraction Osteogenesis. Journal of Craniofacial Surgery 18:6, 1397-1402. [CrossRef]

6. J. Hu, M.C. Qi, S.J. Zou, J.H. Li, E. Luo. 2007. Callus formation enhanced by BMP-7 ex vivo gene therapy during distraction osteogenesis in rats. Journal of Orthopaedic Research 25:2, 241-251. [CrossRef]

7. P. Mark Bartold, Yin Xiao, S. Petter Lyngstaadas, Michael L. Paine, Malcolm L. Snead. 2006. Principles and applications of cell delivery systems for periodontal regeneration. Periodontology 2000 41:1, 123-135. [CrossRef]

8. Darnell Kaigler, Zhuo Wang, Kim Horger, David J Mooney, Paul H Krebsbach. 2006. VEGF Scaffolds Enhance Angiogenesis and Bone Regeneration in Irradiated Osseous Defects. Journal of Bone and Mineral Research 21:5, 735-744. [CrossRef]

9. RM Schek, JM Taboas, SJ Hollister, PH Krebsbach. 2005. Tissue engineering osteochondral implants for temporomandibular joint repair. Orthodontics and Craniofacial Research 8:4, 313-319. [CrossRef]

10. Brian Nussenbaum, R Bruce Rutherford, Paul H. Krebsbach. 2005. Bone Regeneration in Cranial Defects Previously Treated with Radiation. The Laryngoscope 115:7, 1170-1177. [CrossRef]

11. Paul J Harwood, Peter V Giannoudis. 2005. Application of bone morphogenetic proteins in orthopaedic practice: their efficacy and side effects. Expert Opinion on Drug Safety 4:1, 75-89. [CrossRef]

12. Mathew Varkey, Sebastien A Gittens, Hasan Uludag. 2004. Growth factor delivery for bone tissue repair: an update. Expert Opinion on Drug Delivery 1:1, 19-36. [CrossRef]

13. Rachel M. Schek, Juan M. Taboas, Sharon J. Segvich , Scott J. Hollister , Paul H. Krebsbach . 2004. Engineered Osteochondral Grafts Using Biphasic Composite Solid Free-Form Fabricated ScaffoldsEngineered Osteochondral Grafts Using Biphasic Composite Solid Free-Form Fabricated Scaffolds. Tissue Engineering 10:9-10, 1376-1385. [Abstract] [PDF] [PDF Plus]

14. Brian Nussenbaum, Theodoros N Teknos, Douglas B Chepeha. 2004. Tissue engineering: the current status of this futuristic modality in head neck reconstruction. Current Opinion in Otolaryngology \& Head and Neck Surgery 12:4, 311-315. [CrossRef] 